Open Access

\title{
Impact of a methadone maintenance therapy pilot in Vietnam and its role in a scaled-up response
}

Tran Vu Hoang ${ }^{1}$, Tran Thi Thanh Ha², Tran Minh Hoang ${ }^{3}$, Nguyen To Nhu², Nguyen Cuong Quoc ${ }^{2}$, Nguyen thi Minh $\mathrm{Tam}^{4}$ and Stephen Mills ${ }^{5^{*}}$

\begin{abstract}
Background: As a dual response to the HIV epidemic and the high level of injecting drug use in Vietnam, the Ministry of Health $(\mathrm{MOH})$ initiated a pilot methadone maintenance therapy (MMT) program in Hai Phong and Ho Chi Minh City (HCMC) in early 2009. The objectives of the pilot were to provide evidence on whether MMT could be successfully implemented in Vietnam and scaled up to other localities.
\end{abstract}

Methods: A prospective study was conducted among 965 opiate drug users admitted to the pilot. Data on demographic characteristics, sexual behaviors, substance use behaviors (including heroin use), and blood-borne virus infection (HIV, hepatitis B, and hepatitis C) were collected at treatment initiation and then again at 3-, 6-, 9-, 12-, 18-, and 24-month intervals thereafter.

Results: Twenty-four months after treatment initiation, heroin use as measured by urine test or self-report had reduced from $100 \%$ of participants at both sites to $14.6 \%$ in Hai Phong and $22.9 \%$ in HCMC. When adjusted for multiple factors in Generalized Estimating Equations (GEE) logistic regression modeling, independent predictors of continued heroin use after 24 months of MMT in HCMC were the following: poor methadone adherence (adjusted odds ratio $(A O R)=3.7,95 \%$ confidence interval $(\mathrm{Cl})$ 1.8-7.8); currently on antiretroviral treatment (ART) (AOR=1.8, $95 \%$ Cl 1.4-2.4); currently on TB treatment ( $\mathrm{AOR}=2.2,95 \% \mathrm{Cl} 1.4-3.4)$; currently experiencing family conflict ( $\mathrm{AOR}=1.6$, $95 \% \mathrm{Cl} 1.1-2.4$ ); and currently employed ( $\mathrm{AOR}=0.8,95 \% \mathrm{Cl} 0.6-1.0)$.

For Hai Phong participants, predictors were the following: currently on ART (AOR =2.0, $95 \% \mathrm{Cl}=1.4-3.0$ ); currently experiencing family conflict ( $A O R=2.0,95 \% \mathrm{Cl}=1.0-3.9$ ); and moderate adherence to methadone ( $A O R=2.1,95 \% \mathrm{Cl}=1.2-1.9)$. In Hai Phong, the percentage of participants who were employed had also increased by end of study from 35.0 to $52.8 \%$, while in HCMC the level remained relatively unchanged, between 52.2 and $55.1 \%$.

Discussion: Study findings were used in multiple fora to convince policymakers and the public on the significant and vital role MMT can play in reducing heroin use and improving quality of life for individuals and families. Four years after this study was completed, Vietnam had expanded MMT to 162 clinics in 44 provinces serving 32,000 patients.

Keywords: Methadone, Heroin, HIV, Antiretroviral treatment, Vietnam

\footnotetext{
*Correspondence: Smills@fhi360.org

${ }^{5} \mathrm{FHI}$ 360, 19th Floor, Sindhorn Building, Wittayu Road, Bangkok, Thailand

Full list of author information is available at the end of the article
} 


\section{Background}

Methadone maintenance therapy (MMT) using oral methadone was first proposed as a favorable treatment for relieving heroin addiction over 50 years ago and has since been scaled up in numerous countries as an effective intervention for reducing heroin dependence and increasing quality of life [1]. With the advent of the HIV epidemic among people who inject drugs, evidence has shown that methadone increases adherence to antiretroviral therapy [2] and decreases mortality among people living with HIV [3]. MMT has also been shown to be associated with significant reductions in risk behaviors, e.g., injecting drugs, needle sharing, and having multiple sex partners or exchanging of sex for drugs or money [4]. In addition, MMT has been demonstrated to be a cost-effective treatment in several studies [5]. These findings as a whole point to MMT as an integral and essential component of both drug treatment strategies and HIV prevention and treatment strategies.

Since the early 1990s, the HIV epidemic in Vietnam has been predominantly fueled by the sharing of needles and other injecting equipment among people who inject drugs (PWID), mostly heroin [6-10]. HIV prevalence among this population remains as high as $40 \%$ in many locations [11]. It is estimated by 2010 that there were more than 130,000 PWID nationwide in Vietnam [12], though this may be a significant underestimation [13]. Key HIV-related risk behaviors among this population include a continuing high frequency of injection, sharing of used needles and syringes, and unprotected sex with both regular and commercial sex partners [11, 14]. Efforts to improve drug and HIV prevention policies, the provision of harm reduction services, and outreach to rehabilitation services were then initiated in the early 2000 s, [15]. However, one significant barrier to this was that the type of rehabilitation offered was predominantly a network of compulsory rehabilitation centers throughout the country that focused on a mixture of detoxification, labor, and lectures with little evidence-based service and a subsequent high rate of re-incarceration [16].

The next significant event was the MMT pilot discussed here. It was based in part on the observed reduction in heroin use and injection among drug users on MMT already documented in many countries in previous decades [17-20]. The objectives, again, were to provide evidence that MMT could be successfully implemented in Vietnam and scaled up to other localities.

In this paper, we examine the outcomes of this pilot, including prevalence of drug use, factors that predict continued drug use, methadone dosage patterns, and social factors such as employment and social relationships, among patients enrolled in a cohort study at six MMT outpatient clinics in Hai Phong and Ho Chi Minh City (HCMC), Vietnam. We also discuss both technical and policy implications using findings of this analysis.

\section{Methods}

An observational prospective study was conducted among a cohort of participants who were consecutively enrolled in an MMT program in six clinics in Hai Phong and HCMC, Vietnam from January to October 2009. Under the Ministry of Health $(\mathrm{MOH})$ regulations, people with the following characteristics were eligible: they must have been at least 18 years of age; they must have presented with opiate addiction for at least 3 years or more; and they must have voluntarily applied for MMT. Additional inclusion criteria were that participants were able to grant informed consent and had no other serious medical conditions that required hospitalization or extensive medical care.

A total of 965 patients enrolled in this study over the initial 9 months. After 2 years, 751 participants had completed the study and 214 had been lost to follow-up. Among those who were lost to follow-up, 16 had died, 97 had stopped MMT, 38 had withdrawn from the study, and 74 had been arrested. The absolute case number lost to follow-up at 12 months was 113 and at 24 months was 214, leaving 852 participants in the study at 12 months and 751 at the 24-month follow-up. The study retention proportion was $88.3 \%(852 / 965)$ at 12 months and $77.8 \%(751 / 965)$ at 24 months. Total study time was 20,058 person-months.

Each participant was followed up for 24 months, including study visits at enrollment and then at intervals of $3,6,9,12,18$, and 24 months. At each visit, participants underwent an individual interview with a trained interviewer using a structured questionnaire. Information on treatment progress was also collected from patient medical records. Urine samples were collected to provide a biological marker of opiate use and participants were asked to provide $5-\mathrm{ml}$ venous blood for detection of HIV, hepatitis B, and hepatitis $C$ at each data collection interval.

The structured questionnaire for individual interviews included questions about participants' characteristics (at baseline), drug use, sexual behaviors, living arrangements, employment, quality of life, and legal status including criminal activities. Questions on sexual and injecting risk behaviors were adopted from standardized questionnaires previously used for HIV/STI behavioral surveillance in Vietnam. Questions on injecting behaviors included history of injecting and detoxification, drug types and modes of use, frequency of use, and needle sharing. Sexual behavior questions covered sexual history, types and numbers of sex partners, and condom use. Timeframes of variables of interest depended on intervals between visits ( 3 months in the first year and 
6 months in the second year). Questions were also asked on drug use in the 30 days prior to interview.

Participants' quality of life was measured using a WHO module known as WHO QOL-BREF [21]. This tool has been widely used in health research in Vietnam and other countries [22, 23]. It includes 28 items measuring four domains of health: physical, psychological, social, and environment. Data were then extracted from patient clinical files, including assessment forms used in counseling sections with pre-structured data collection forms. Patients' daily methadone doses were also taken from methadone dispensing databases.

The markers for heroin use were then derived from urinalysis. During treatment of patients, a series of urine tests was conducted by the clinic randomly at least once per month or by physician's direction when drug use was suspected. Urine tests were also conducted at baseline, $3,6,9,12,18$, and 24 months at study sites by trained technicians. The study team then used InstantView Morphine (300) Urine Test (Dip-Strip) test kits (ALFA Scientific designs Inc.) for detection of morphine biomarkers.

To generate the variable of concurrent heroin use, a study subject was defined as continuing illicit heroin use if in the course of two intervals, they had at least one positive urine test (by random testing, by physician's decision, or at initial interview) or if they self-reported continued drug use in the behavioral section of the interview questionnaire.

The study team used Abbott Determine ${ }^{\mathrm{Tx}} \mathrm{HBsAg}$ test kits for detecting HBsAg and SD Bioline HCV test kits for identifying $\mathrm{HCV}$ antibodies, both in patient plasma. Specimens were collected by a technician at study site and transported to microbiology labs at preventive medicine centers in HCMC and Hai Phong.

HIV tests were performed following standard HIV diagnostic algorithms approved by the $\mathrm{MOH}$. Screening was performed using Genscreen Ultra HIV $\mathrm{Ag} / \mathrm{Ab}$ (Biorad, US) and then confirmed by rapid test (Determine HIV-1/2 (Alere, Japan)) and EIA test Murex HIV $\mathrm{Ag} / \mathrm{Ab}$ (Dia Sorin, UK). The testing was conducted by lab technicians at provincial HIV/AIDS centers (PACs). The lab and technicians were certified by the National Reference Laboratory at the National Institute of Hygiene and Epidemiology (NIHE). Data were entered at study sites using Microsoft Access (Microsoft Inc, 2007), and data cleaning was performed after each round of study visits.

Data analyses were performed separately for respondents in Hai Phong and HCMC. Descriptive analyses were employed for participants' social and behavioral characteristics. Trend analysis using random effects logistic regression was used to show changes in drug use by treatment period at intervals of $3,6,9,12,18$, and
24 months after enrollment. Univariate analysis was then used to assess the association between heroin use (dependent variable) and other independent variables. Any independent variables that had a statistically significant association with the dependent variable $(p$ value $<0.05)$ were included in the final model.

General estimating equation (GEE) logistic regression with random effects was used to take into account the fact that each participant was measured multiple times in the study for both dependent and independent variables. The GEE regression-based approach allowed for more comprehensive use of correlated data and for more reliable estimates in the study of substance use [24]. Variables significant from univariate analyses were added into the models using a stepwise procedure.

The study protocol, informed consent, and data collection forms were reviewed and approved by the FHI 360 Protection of Human Subjects Committee in North Carolina, USA, and by the Hanoi School of Public Health in Vietnam.

\section{Results}

Demographic characteristics of study participants are presented in Table 1. Patients had used heroin an average of 10 years prior to initiating MMT (9.7 years among participants in Hai Phong and 9.6 years among participants in HCMC). More than $60 \%$ of participants used heroin two to three times per day and one-third used it four times or more per day. At enrollment, $81.2 \%$ of participants in Hai Phong and $87 \%$ in HCMC were injecting. Just $15 \%$ of participants in Hai Phong reported having ever being in mandatory detoxification centers, and $45.6 \%$ of participants in HCMC reported having been in these centers at least once.

At baseline, $26.6 \%$ of participants in Hai Phong and $37.2 \%$ in HCMC were HIV-positive $(p<0.01)$. The prevalence of HBV was $11.8 \%$ in Hai Phong and $20.6 \%$ in HCMC $(p<0.01)$. HCV prevalence was much higher among study participants: $40 \%$ in Hai Phong and $69.8 \%$ in HCMC $(p<0.01)$.

Figure 1 shows trends of concurrent heroin use among study participants. Where any patient had at least one of the following conditions in the 30 days prior to the study visit, "heroin use" was confirmed: (1) they self-reported drug use, (2) they tested positive for opiates in a urine test conducted by a clinician, or (3) they tested positive for opiates in a urine test conducted during a study visit.

The largest decreases in heroin use were observed in the period between the enrollment visit (baseline) and the 3-month visit. Among the entire body of participants using heroin at initiation of MMT, only $34.6 \%$ in Hai Phong were still using it after 3 months, and in HCMC, $36.2 \%$ of participants were still using after 3 months. This trend continued to the 6 -month visit as well, with 
Table 1 Characteristics of MMT participants at baseline $(n=965)$

\begin{tabular}{|c|c|c|c|c|}
\hline & Hai Phong & HCMC & Total & $p$ value \\
\hline & $\%(n)$ & $\%(n)$ & $\%(n)$ & \\
\hline \multicolumn{5}{|l|}{ Gender } \\
\hline Male & $98.1(458)$ & $92.0(458)$ & $94.9(916)$ & \multirow[t]{2}{*}{$0.000^{b}$} \\
\hline Female & $1.9(9)$ & $8.0(40)$ & $5.1(49)$ & \\
\hline Age-mean (SE) & $34.4(0.1)$ & $30.1(0.1)$ & $32.3(0.1)$ & $0.000^{c}$ \\
\hline Under 20 & $2.8(13)$ & $1.0(5)$ & $1.9(18)$ & \multirow[t]{4}{*}{$0.000^{d}$} \\
\hline 20 to 25 & $10.3(48)$ & $15.7(78)$ & $13.1(126)$ & \\
\hline 25 to 29 & $19.1(89)$ & $45.9(228)$ & $32.9(317)$ & \\
\hline 30 or more & $67.9(317)$ & $37.4(186)$ & $52.2(503)$ & \\
\hline \multicolumn{5}{|l|}{ Education } \\
\hline No school & $0.6(3)$ & $0.8(4)$ & $0.7(7)$ & \multirow[t]{5}{*}{$0.631^{d}$} \\
\hline Primary school & $8.8(41)$ & $10.6(53)$ & $9.7(94)$ & \\
\hline Secondary school & $44.1(206)$ & $46.8(233)$ & $45.5(439)$ & \\
\hline High school & $42.2(197)$ & $38.0(189)$ & $40.0(386)$ & \\
\hline College/university & $4.3(20)$ & $3.8(19)$ & $4.0(39)$ & \\
\hline Monthly income - mean in US\$ (SE) & $285.5(11.2)$ & $292.4(13.8)$ & $289.1(8.9)$ & $0.699^{c}$ \\
\hline Duration of drug use-mean in year (SE) & $9.7(0.2)$ & $9.6(0.2)$ & $9.7(0.1)$ & $0.596^{c}$ \\
\hline \multicolumn{5}{|l|}{ Frequency of heroin use at baseline } \\
\hline Once per day & $1.1(5)$ & $2.4(12)$ & $1.8(17)$ & \multirow[t]{3}{*}{$0.256^{\mathrm{b}}$} \\
\hline 2 to 3 times/day & $62.9(291)$ & $63.6(316)$ & $63.2(607)$ & \\
\hline 4 times or more per day & $36.1(167)$ & $34.0(169)$ & $35.0(336)$ & \\
\hline \multicolumn{5}{|l|}{ Methods of administering drug in the 30 days prior to MMT enrollment } \\
\hline Injecting & $81.2(379)$ & $87.0(433)$ & $84.2(812)$ & $0.014^{\mathrm{b}}$ \\
\hline Inhaling & $21.6(101)$ & $18.7(93)$ & $20.1(194)$ & $0.253^{b}$ \\
\hline Had ever been in state-operated drug rehabilitation centers ("06 centers") & $15.0(70)$ & $45.6(227)$ & $30.8(297)$ & $0.000^{b}$ \\
\hline Had had sex with regular partners & $46.7(218)$ & $43.4(216)$ & $45.0(434)$ & $0.302^{b}$ \\
\hline Had had commercial sex in the previous 3 months & $3.6(17)$ & $2.6(13)$ & $3.1(30)$ & $0.357^{b}$ \\
\hline Had a regular sex partner who was also PWID & $7.5(35)$ & $14.5(72)$ & $11.1(107)$ & $0.001^{b}$ \\
\hline HIV-positive & $26.6(124)$ & $37.2(146)^{\mathrm{a}}$ & $31.4(270)$ & $0.001^{b}$ \\
\hline Hepatitis B positive & $11.8(55)$ & $20.6(102)$ & $16.3(157)$ & $0.000^{b}$ \\
\hline Hepatitis C positive & $40.0(187)$ & $69.8(346)$ & $55.4(533)$ & $0.000^{b}$ \\
\hline
\end{tabular}

In 392 participants (out of 498) who agreed to provide blood samples for HIV test or had HIV test results in their medical records at MMT clinics

${ }^{\mathrm{b}} \mathrm{Chi}$-square test

${ }^{\mathrm{C}} T$ test

'Fisher's exact test

$19.4 \%$ of participants in Hai Phong and $25.5 \%$ in HCMC still using heroin in the 30 days prior to the 6month follow-up interview. Then at the 24-month follow-up, $22.9 \%$ of participants in Hai Phong and $14.6 \%$ of participants in HCMC were still using heroin.

Table 2 shows the trends in methadone, antiretroviral treatment (ART), and tuberculosis (TB) treatment. After 3 months, the mean dosage of methadone among patients in Hai Phong was $9.6 \mathrm{ml}$, and in HCMC, this was $10.6 \mathrm{ml}$. There was a marked difference in dosing between Hai Phong and HCMC: the mean dosage among Hai Phong participants stabilized at
9.6 $\mathrm{ml}$, where the mean among HCMC participants had increased from $10.5 \mathrm{ml}$ at 3 months to $11.6 \mathrm{ml}$ at 24 months. Adherence did decline in both cities: $18.4 \%$ of participants reported missing one or two doses in the first 3 months, and by 24 months, this figure had increased to $41.4 \%$ for the 6 months prior to final study visit. Percentage of patients who had missed three or four doses also increased from $1.0 \%$ at 3 months to $3.7 \%$ in the final 6 months. The data further showed that in the final 6 months, $3.7 \%$ of participants had missed doses for a continuous 5 days or more. 


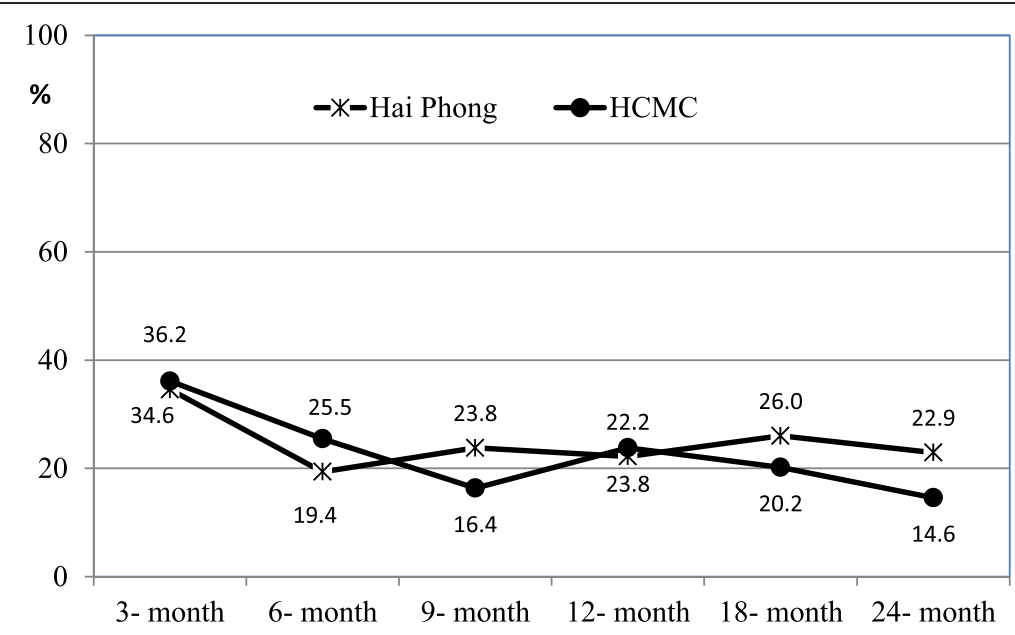

Fig. 1 Trends in heroin use over time among participants

At baseline visit, $27.2 \%$ of participants were on ART, and by the end of month 24 , this figure was $29.2 \%$. Notably, the proportion of patients who were on ART was higher in HCMC than it was in Hai Phong. At the end of the study follow-up period, $43.3 \%$ of the HIV-positive patients in HCMC were receiving ARVs and $16 \%$ of the HIV-positive patients in Hai Phong were receiving them.

Employment status and family characteristics are then presented in Table 3. In univariate analysis, factors that were statistically associated with concurrent heroin use

Table 2 Methadone and ART

\begin{tabular}{|c|c|c|c|c|c|c|c|}
\hline & \multicolumn{6}{|c|}{ Follow-up periods } & \multirow[t]{2}{*}{$p$ value } \\
\hline & $\begin{array}{l}0-3 \text { months } \\
(n=930)\end{array}$ & $\begin{array}{l}4-6 \text { months } \\
(n=900)\end{array}$ & $\begin{array}{l}\text { 7-9 months } \\
(n=871)\end{array}$ & $\begin{array}{l}10-12 \text { months } \\
(n=852)\end{array}$ & $\begin{array}{l}13-18 \text { months } \\
(n=802)\end{array}$ & $\begin{array}{l}\text { 19-24 months } \\
(n=751)\end{array}$ & \\
\hline \multicolumn{8}{|c|}{ Mean methadone doses at study visits, in $\mathrm{ml}$ (SE) } \\
\hline Hai Phong & $9.6(0.2)$ & $9.9(0.2)$ & $9.5(0.2)$ & $9.5(0.3)$ & $9.4(0.3)$ & $9.6(0.3)$ & $0.248^{\mathrm{a}}$ \\
\hline $\mathrm{HCMC}$ & $10.6(0.2)$ & $11.0(0.3)$ & $11.2(0.3)$ & $11.4(0.3)$ & $11.5(0.4)$ & $11.6(0.4)$ & $0.000^{\mathrm{a}}$ \\
\hline Total & $10.1(0.1)$ & $10.4(0.2)$ & $10.4(0.2)$ & $10.4(0.2)$ & $10.4(0.2)$ & $10.6(0.3)$ & $0.000^{\mathrm{a}}$ \\
\hline \multicolumn{8}{|c|}{ Missed methadone dose for $1-2$ days, in $\%$} \\
\hline Hai Phong & 19.5 & 23.6 & 30.7 & 41.1 & 48.4 & 47.7 & $0.000^{\mathrm{a}}$ \\
\hline $\mathrm{HCMC}$ & 17.3 & 22.0 & 26.5 & 28.1 & 33.8 & 34.7 & $0.000^{\mathrm{a}}$ \\
\hline Total & 18.4 & 22.8 & 28.6 & 34.6 & 41.3 & 41.4 & $0.000^{\mathrm{a}}$ \\
\hline \multicolumn{8}{|c|}{ Missed methadone doses for continuous 3-4 days, in \% } \\
\hline Hai Phong & 1.3 & 0.9 & 1.8 & 1.9 & 2.2 & 3.4 & $0.009^{\mathrm{a}}$ \\
\hline $\mathrm{HCMC}$ & 0.6 & 0.9 & 1.4 & 0.7 & 1.0 & 4.1 & $0.000^{\mathrm{a}}$ \\
\hline Total & 1.0 & 0.9 & 1.6 & 1.2 & 1.6 & 3.7 & $0.000^{\mathrm{a}}$ \\
\hline \multicolumn{8}{|c|}{ Missed methadone doses for a continuous 5 days or more, in \% } \\
\hline Hai Phong & 0.9 & 1.1 & 1.1 & 1.2 & 2.2 & 2.3 & $0.025^{\mathrm{a}}$ \\
\hline $\mathrm{HCMC}$ & 1.3 & 0.9 & 1.4 & 0.9 & 3.3 & 4.1 & $0.000^{\mathrm{a}}$ \\
\hline Total & 1.1 & 1.0 & 1.3 & 1.1 & 2.7 & 3.2 & $0.000^{\mathrm{a}}$ \\
\hline \multicolumn{8}{|c|}{ ARV treatment, in $\%$} \\
\hline Hai Phong & 14.2 & 12.9 & 15.1 & 14.0 & 16.3 & 16.0 & $0.202^{\mathrm{a}}$ \\
\hline HCMC & 39.8 & 50.8 & 35.9 & 38.7 & 41.2 & 43.3 & $0.846^{\mathrm{a}}$ \\
\hline Total & 27.2 & 31.9 & 25.5 & 26.3 & 28.4 & 29.2 & $0.827^{\mathrm{a}}$ \\
\hline
\end{tabular}

${ }^{\mathrm{a}}$ Test for trend 
Table 3 Participants' social characteristics and behaviors

\begin{tabular}{|c|c|c|c|c|c|c|c|}
\hline \multirow{3}{*}{$\begin{array}{l}\text { Variables of } \\
\text { interest }\end{array}$} & \multicolumn{6}{|c|}{ Follow-up periods } & \multirow[t]{3}{*}{$p$ value } \\
\hline & $0-3$ months & 4-6 months & 7-9 months & 10-12 months & 13-18 months & 19-24 months & \\
\hline & $(n=930)$ & $(n=900)$ & $(n=871)$ & $(n=852)$ & $(n=802)$ & $(n=751)$ & \\
\hline \multicolumn{8}{|c|}{ Percent of participants who were employed full-time and had stable monthly income $(n)$} \\
\hline Hai Phong & 35.0 & 47.4 & 49.0 & 54.4 & 51.6 & 52.8 & $0.000^{\mathrm{a}}$ \\
\hline HCMC & 52.2 & 57.9 & 61.5 & 56.1 & 53.2 & 55.1 & $0.705^{\mathrm{a}}$ \\
\hline Total & 43.8 & 52.7 & 55.2 & 55.3 & 52.4 & 53.9 & $0.002^{\mathrm{a}}$ \\
\hline \multicolumn{8}{|c|}{ Percent of participants who reported having conflict within their family } \\
\hline Hai Phong & 2.0 & 3.8 & 2.8 & 2.3 & 0.7 & 0.8 & $0.005^{\mathrm{a}}$ \\
\hline $\mathrm{HCMC}$ & 17.3 & 3.1 & 4.2 & 2.6 & 6.1 & 3.9 & $0.000^{\mathrm{a}}$ \\
\hline Total & 9.8 & 3.4 & 3.4 & 2.5 & 3.4 & 2.3 & $0.000^{\mathrm{a}}$ \\
\hline \multicolumn{8}{|c|}{ Percent of participants who reported having troubled relationships with family and community members } \\
\hline Hai Phong & 2.4 & 3.1 & 1.8 & 2.3 & 2.2 & 1.8 & $0.394^{\mathrm{a}}$ \\
\hline $\mathrm{HCMC}$ & 9.7 & 9.8 & 5.3 & 5.9 & 6.1 & 4.4 & $0.001^{\mathrm{a}}$ \\
\hline Total & 6.1 & 6.4 & 3.6 & 4.1 & 4.1 & 3.1 & $0.001^{a}$ \\
\hline
\end{tabular}

${ }^{\mathrm{a}}$ Test for trend

were different for the two cities. In Hai Phong, they included having conflict in the family (odds ratio (OR): 2.0; $95 \%$ confidence interval (CI): 1.0 4.0), higher methadone dosage (OR: 1.2; 95 \% CI: 1.0-1.3), moderate level of adherence to methadone treatment (OR: 1.5; $95 \%$ CI: 1.2-1.8), and currently on ART (OR: 2.2; $95 \%$ CI: 1.5-3.1). In HCMC, more factors were found associated with concurrent heroin use among participants, including both protective and risk factors. Protective factors included age (OR: 0.8; $95 \% \mathrm{CI}: 0.7-0.9$ ) and being employed full-time (OR: 0.7; 95 \% CI: 0.6-0.9). Risk factors included having conflict in the family (OR: 1.9; $95 \%$ CI: 1.3-2.7), living with injecting family members (OR: 1.7; 95 \% CI: 1.0-3.0), higher methadone dosage (OR: 1.2; $95 \% \mathrm{CI}$ : 1.1-1.3), level of adherence in follow-up periods (for moderate adherence: OR: 1.5; $95 \%$ CI: 1.2-1.9, for poor adherence: OR: 3.5 ; $95 \%$ CI:1.77.1), currently on ART (OR: 2.1; $95 \%$ CI 1.6-2.9), and currently on TB treatment (OR: 3.0; $95 \%$ CI: 2.0-4.6) (Table 4).

In the final model for Hai Phong (Table 5), independent predictors of continued heroin use were the following: currently on ART (adjusted odds ratio $(\mathrm{AOR})=2.0$, $95 \% \mathrm{CI}=1.4-3.0)$; currently experiencing family conflict $(\mathrm{AOR}=2.0,95 \% \mathrm{CI}=1.0-3.9)$; and moderate adherence to methadone $(\mathrm{AOR}=1.5,95 \% \mathrm{CI}=1.2-1.9)$.In the final model for HCMC (Table 6), independent predictors of continued heroin use were the following: currently on ART (adjusted odds ratio $(\mathrm{AOR})=1.8$, $95 \% \mathrm{CI}=1.4-$ 2.4 ); currently experiencing family conflict $(\mathrm{AOR}=1.6$, $95 \% \mathrm{CI}=1.1-2.4)$; and moderate adherence to methadone $(\mathrm{AOR}=1.7,95 \% \mathrm{CI}=1.3-2.2)$.
In $\mathrm{HCMC}$, independent predictors of continued heroin use after 24 months of MMT were the following: poor adherence $(\mathrm{AOR}=3.7,95 \% \mathrm{CI} 1.8-7.8)$; currently on ART $(\mathrm{AOR}=1.8,95 \% \mathrm{CI} 1.4-2.4)$; currently on TB treatment $(\mathrm{AOR}=2.2$, $95 \% \mathrm{CI} 1.4-3.4)$; currently experiencing family conflict $(\mathrm{AOR}=1.6,95 \% \mathrm{CI} 1.1-2.4)$; and currently employed (AOR $=0.8,95 \%$ CI 0.6-1.0).

\section{Discussion}

This study showed that MMT among people who injected opioid drugs in the two cities led to improved quality of life in terms of reduced drug use, higher levels of employment, and reduced conflicts among families and communities. The reductions in drug use found in this study were comparable to that found in other studies [19, 25-29]. For example, in a recent cross-sectional survey in nine provinces in China, $27 \%$ of patients on MMT were found to be still using opiates after 2 years of MMT, compared to $20 \%$ in this study [30].

The data also showed high prevalence of HIV among MMT patients, at $26.6 \%$ in Hai Phong and $37.2 \%$ in HCMC. Approximately half of the HIV-positive individuals in the Hai Phong sample and almost all of the HIVpositive individuals in the HCMC sample were on ART. In both cities, patients who were on ART were more likely to continue to use heroin compared to patients not on ART. This may be due to the fact that ART allows very ill patients to return to their previous lifestyles, which in this case includes drug use. ART can also decrease methadone levels, and so, this may have also led to increased recidivism to drug use among patients on ART whose methadone dosages were not adjusted [31]. 
Table 4 Bivariate analyses of risk factors for concurrent heroin use among MMT patients

\begin{tabular}{|c|c|c|c|c|}
\hline & \multicolumn{2}{|l|}{ Hai Phong } & \multicolumn{2}{|l|}{$\mathrm{HCMC}$} \\
\hline & Unadjusted OR & $95 \% \mathrm{Cl}$ & Unadjusted OR & $95 \% \mathrm{Cl}$ \\
\hline Age (in 5-year units) & 0.9 & $0.8-1.0$ & 0.8 & $0.7-0.9$ \\
\hline Gender (male is reference) & 0.7 & $0.2-2.0$ & 0.7 & $0.4-1.2$ \\
\hline Ever been in an 06 center (yes/no) & 1.0 & $0.7-1.5$ & 1.1 & $0.8-1.5$ \\
\hline Being employed full-time (yes/no) & 1.1 & $0.9-1.4$ & 0.7 & $0.6-0.9$ \\
\hline Had problematic relation with family and/or community members (yes/no) & 0.7 & $0.3-1.6$ & 1.4 & $0.9-2.0$ \\
\hline Had negative activities in family (yes/no) & 2.0 & $1.0-4.0$ & 1.9 & $1.3-2.7$ \\
\hline Involved in criminal activities (yes/no) & 1.2 & $0.6-2.2$ & 1.6 & $0.6-4.2$ \\
\hline Had PWID sex partners (yes/no) & 1.2 & $0.4-3.6$ & 1.3 & $0.9-1.8$ \\
\hline Had PWID cohabitants (yes/no) & 0.9 & $0.5-1.9$ & 1.7 & $1.0-3.0$ \\
\hline Methadone dosage (in 5-ml units) & 1.2 & $1.0-1.3$ & 1.2 & $1.1-1.3$ \\
\hline \multicolumn{5}{|l|}{ Adherence to $\mathrm{MMT}^{\mathrm{a}}$} \\
\hline Good adherence & 1 & - & - & - \\
\hline Moderate adherence & 1.5 & $1.2-1.8$ & 1.5 & $1.2-1.9$ \\
\hline Poor adherence & 1.9 & $0.8-4.5$ & 3.5 & $1.7-7.1$ \\
\hline Current ART (yes/no) & 2.2 & $1.5-3.1$ & 2.1 & $1.6-2.9$ \\
\hline Current TB treatment (yes/no) & 0.9 & $0.1-5.9$ & 3.0 & $2.0-4.6$ \\
\hline
\end{tabular}

${ }^{a}$ Adherence level was defined as the following: good: no dose missed; moderate: missed doses for 1 to 4 continuous days; poor: missed doses for 5 or more continuous days

Several studies have shown the relationship between methadone dosage and drug use behaviors, with higher dosages associated with lower drug use [25, 32, 33]. However, in this study, no relationship between concurrent heroin use and methadone dosage was actually found. The results strongly suggest the need for appropriate clinical guidelines for methadone dose determination, however, particularly for patients who are also on ART.

Similarly, the data showed that TB treatment also increased the likelihood of continuing heroin use among MMT patients in HCMC. This is in agreement with findings from other studies, which show that rifampicin reduces the half-life of methadone, that $\mathrm{TB}$ is common among drug users who are HIV-positive, and that there is a need to consider TB status and treatment in determining methadone dosage for patients [34, 35].

Table 5 Multivariate analysis of factors associated with concurrent heroin use among MMT patients in Hai Phong

\begin{tabular}{lll}
\hline & Adjusted $\mathrm{OR}^{\mathrm{a}}$ & $95 \% \mathrm{Cl}$ \\
\hline Had conflict in the family (yes/no) & 2.0 & $1.0-3.9$ \\
Adherence to MMT & 1 & - \\
Good & 1.5 & $1.2-1.9$ \\
Moderate & 2.1 & $0.9-5.0$ \\
Poor & 2.0 & $1.4-3.0$ \\
\hline ARV treatment (yes/no) &
\end{tabular}

${ }^{a}$ Adjusted for age, gender, and methadone dose
The findings that patients' adherence to methadone reduced with time in MMT and that poor adherence increased the risk of relapse to drug use and the likelihood of program withdrawal are supported by other studies [36]. Furthermore, the associations between adherence and heroin use, not only for those with poor adherence but also for patients who missed just one or two doses, strongly suggests that monitoring patient adherence will help to monitor treatment failure. An early warning system using data from methadone dispensing may be useful to provide necessary and timely support to concurrent heroin users. Future studies to

Table 6 Multivariate analyses of factors associated with concurrent heroin use among MMT patients in HCMC

\begin{tabular}{lll}
\hline & Adjusted OR $^{\mathrm{a}}$ & $95 \% \mathrm{Cl} ; p$ value \\
\hline Age (in 5 year units) & 0.8 & $0.7-0.9 ; 0.00$ \\
Being employed full-time (yes/no) & 0.8 & $0.6-1.0 ; 0.05$ \\
Had conflict in the family (yes/no) & 1.6 & $1.1-2.4 ; 0.03$ \\
Adherence to MMT & & \\
$\quad$ Good & 1.7 & $1.3-2.2 ; 0.00$ \\
$\quad$ Moderate & 3.7 & $1.8-7.8 ; 0.00$ \\
$\quad$ Poor & 1.8 & $1.4-2.4 ; 0.00$ \\
ART (yes/no) & 2.2 & $1.4-3.4 ; 0.00$ \\
TB treatment (yes/no)
\end{tabular}

${ }^{\mathrm{a}}$ Adjusted for gender, ever been in a rehabilitation center, had a PWID cohabitant or regular sex partner, problematic relationship with family or community members, and methadone dosage 
understand patterns and reasons for non-adherence among people who use heroin are thus needed.

In HCMC, the finding that patients who had full-time employment and stable incomes also had a $20 \%$ lower likelihood of continuing heroin use may be interpreted in two different ways: patients with stable jobs were more likely to stop heroin, or heroin abstainers were more likely to find a job. However, both interpretations indicate that MMT is more successful when it is supplemented with other social support services to help heroin users re-integrate into their communities.

Rates of HBV and HCV were both high in the samples in this study, with almost one in six infected with HBV and over half infected with HCV. These rates reinforce the need for both scaled-up HBV vaccination programs and scaled-up treatment management of both HBV and HCV among people who inject drugs (PWID), to monitor the onset and progression of liver disease and liver cancer.

The study had several limitations. Most notably, the sample of individuals consisted of patients selected to participate in a pilot program prior to a scaled-up response. Qualitative evidence from health providers suggests that these individuals may have been more motivated, had higher incomes, and come from more stable families than those in the general drug user population.

Males were also predominant in this study (98.1\% of the sample in Hai Phong and $92 \%$ in HCMC), and this reflects existing estimates that the drug use population in Vietnam is over $95 \%$ male [13]. Nevertheless, female drug use remains a critical issue in the country because it is highly related to sex work and HIV infection among sex workers. Because of the low sample size of females in this study, we were unable to make any conclusions regarding their methadone use and related outcomes among them. This remains a critical issue to address in further research.

Furthermore, the loss to follow-up of a sizeable portion of the cohort (22\%) also biased outcomes in an indeterminate way. Of the 214 individuals who were lost to follow-up, 74 of them had been arrested, however, representing over one-third of those who did not continue with the study. Yet, it was not possible to determine whether they were arrested for drug use or other reasons. However, the large number of arrests does suggest that increased cooperation with law enforcement is needed to ensure that PWID seeking and starting MMT are encouraged to continue treatment.

\section{Conclusions}

The positive results of this study, combined with reports from individual families on the positive impacts of MMT on family stabilization and employment and qualitative evidence showing reductions in crime in areas where the pilot was located were the key in convincing policymakers to consider MMT as feasible and valuable, both for the control of HIV as well as drug use reduction. Study results were presented to policymakers at the provincial and national levels in numerous fora. A national media campaign called Methadone is the Smart Solution: Health for Patients, Hope for Families, and Safety for Communities used results from the pilot, family accounts, and positive community reactions to counter false perceptions of methadone and advocate for broader national and provincial support. A national policy was finally signed in 2011 approving the scale-up of MMT in all provinces, removing barriers to implementation and simplifying methadone licensing. By June 2015, Vietnam had expanded MMT to 162 clinics in 44 provinces serving 32,000 patients, with plans for continued scale-up.

This rollout of MMT throughout the country following advocacy and policy-level interventions that proactively used study results demonstrates the positive impacts of a carefully planned pilot of a sensitive new intervention and data on its effectiveness, safety, and impacts.

\section{Competing interests}

The authors declare that they have no competing interests.

\section{Authors' contributions}

TVH designed the study, led the data analysis, and drafted the manuscript. TTH supervised the data collection and also participated in the data analysis. $\mathrm{TMH}$ conducted the statistical analyses and participated in the data analysis. NN participated in the study design, questionnaire construction, data analysis, and manuscript writing. NQ participated in study design and manuscript writing. NT participated in the design of the study and the interpretation of the results. SM conceived of the study and participated in the writing and editing of the manuscript. All authors read and approved the final manuscript.

\section{Acknowledgements}

The authors gratefully thank the Ho Chi Minh and Hai Phong Provincial AIDS Centers, Hai Phong Medical University, and the Ho Chi Minh City Public Health Association for their valuable contribution in data collection for this study. This study was supported by the United States Agency for International Development (USAID) in Vietnam through the HIV/AIDS Prevention, Care, and Treatment Project, Cooperative Agreement number 486-A-00-06-00009-00 and the Sustainable Management of the HIV/AIDS Response and Transition to Technical Assistance (SMART TA) Project, Cooperative Agreement No. 486-A-11-00011, both managed by FHI 360, as part of the United States President Emergency Plan for AIDS Relief (PEPFAR).

\section{Author details}

'Partners in Health Research, 47 Yen Phu Street, Tay Ho District, Hanoi, Vietnam. ${ }^{2} \mathrm{FHI}$ 360, 7th floor, Hanoi Tourist Building, 8 Ly Thuong Kiet Street, Hanoi, Vietnam. ${ }^{3}$ Hanoi Medical University, No. 1, Ton That Tung Street, Hanoi, Vietnam. ${ }^{4}$ Vietnam Administration for AIDS Control, Vietnam Ministry of Health, 5th floor, 138a Giang Vo Street, Ba Dinh District, Hanoi, Vietnam. ${ }^{5} \mathrm{FHI}$ 360, 19th Floor, Sindhorn Building, Wittayu Road, Bangkok, Thailand. 


\section{References}

1. Mattic RP, Breen C, Kimber J, Davoli M, Methadone maintenance therapy versus no opioid replacement therapy for opioid dependence. Cochrane Database Syst Rev. 2009;3:CD002209.

2. Uhlmann S, Milloy M-J, Kerr T, Zhang R, Guillemi S, Marsh, D, et al. Methadone maintenance therapy promotes initiation of antiretroviral therapy among injection drug users. Addiction. 2010;105(5):907-13.

3. Langendam MW, van Brussel, GHA, Coutinho RA, van Ameijden, EJC, et al. The impact of harm-reduction-based methadone treatment on mortality among heroin users. Am J Public Health. 2001;91(5):774-80.

4. Gowing L, Farrell M, Bornemann R, Ali R, (2008) Substitution treatment of injecting opioid users for prevention of HIV infection. Cochrane Database of Syst Rev, doi:10.1002/14651858.CD004145.pub3.

5. Connock M, Juarez-Garcia A, Jowett S, Frew E, Liu Z, Taylor RJ, et al. Methadone and buprenorphine for the management of opioid dependence: a systematic review and economic evaluation. Health Technol Assess. 2007;11(9):1-171.

6. Hien NT, Giang LT, Binh PN, Deville W, Van Ameijden EJC, Wolffers I. Risk factors of HIV infection and needle sharing among injecting drug users in Ho Chi Minh City, Vietnam. J Subst Abuse. 2001;13(1-2):45-58.

7. Lindan CP, Lieu TX, Giang LT, Lap VD, Thuc NV, Thinh T, et al. Rising HIV infection rates in Ho Chi Minh City herald emerging AIDS epidemic in Vietnam. AIDS. 1997;11 Suppl 1:S5-13.

8. Chung A, Vu MQ, Dondero TJ. HIV epidemiologic situation in Vietnam: a review of available data. AIDS. 1998;12(Suppl B):S43-9.

9. Nguyen $T A$, Hoang $L T$, Pham VQ, Detels R. Risk factors for HIV-1 seropositivity in drug users under 30 years old in Haiphong, Vietnam. Addiction. 2001;96(3):405-13.

10. Nguyen TH, Wolffers I. HIV infection in Vietnam. Lancet. 1994;343(8894):410.

11. Vietnam Ministry of Health, FHI360, HIV/STI integrated behavioral and biological surveillance in Vietnam 2006, 2007. Available at: http:// www.aidsdatahub.org/sites/default/files/documents/ Results_from_the_2006_Integrated_ Biological_and_Behavioral_Survey_IBBS_2005_06_Report.pdf.pdf

12. MOLISA. Overview of the impact of policies on drug rehabilitation treatment on its implementation in Vietnam. Ministry of Labor, Invalids, and Social Affairs of Vietnam, Hanoi, 2010.

13. Nguyen VT, Scannapieco M. Drug abuse in Vietnam: a critical review of the literature and implications for future research. Addiction. 2008;103(4):535-43.

14. Nguyen TH, Le TG, Phan NB, Wolffers I. The social context of HIV risk behaviour by drug injectors in Ho Chi Minh City, Vietnam. AIDS Care. 2000;12(4):483-95.

15. Quan VM, Chung A, Long HT, Dondero TJ. HIV in Vietnam: the evolving epidemic and the prevention response, 1996 through 1999. J Acquir Immune Defic Syndr. 2000;25(4):360-9.

16. Vuong T, Ali R, Baldwin S, Mills S. Drug policy in Vietnam: a decade of change?, Int J Drug Policy. 2011;23(4):319-26.

17. Metzger DS, Woody GE, McLellan AT, O'Brien CP, Druley P, Navaline H, et al. Human immunodeficiency virus seroconversion among intravenous drug users in- and out-of-treatment: an 18-month prospective follow-up. J Acquir Immune Defic Syndr. 1993;6(9):1049-56.

18. Pang L, Hao Y, Mi G, Wang C, Luo W, Rou K, et al. Effectiveness of first eight methadone maintenance treatment clinics in China. AIDS. 2007;21 Suppl 8:S103-7.

19. Camacho LM, Bartholomew NG, Joe GW, Simpson DD. Maintenance of HIV risk reduction among injection opioid users: a 12 month posttreatment follow-up. Drug Alcohol Depend. 1997:47(1):11-8.

20. Kwiatowski CF, Booth RE. Methadone maintenance as HIV risk reduction with street-recruited injecting drug users. J Acquir Immune Defic Syndr. 2001;26(5):483-9.

21. Development of the World Health Organization WHOQOL-BREF quality of life assessment. The WHOQOL Group. Psychol Med. 1998;28(3):551-8.

22. Hsiung P-C, Fang C-H, Sheng W-H, Chen S-C, Wang J-D, Yao G. Validation of the WHOQOL-HIV BREF among HIV-infected patients in Taiwan. AIDS Care. 2011;23(8):1035-42.

23. Saddki N, Noor MN, Norbanee MA, Rusli Z, Norzila S, Zaharah A. et al. Validity and reliability of the Malay version of WHOQOL-HIV BREF in patients with HIV infection. AIDS Care. 2009;21(10):1271-8.

24. Homish GH, Edwards EP, Eiden RD, Leonard KE. Analyzing family data: a GEE approach for substance use researchers. Addict Behav. 2010;35(6):558-63.
25. Caplehorn JRM, Bell J, Kleinbaum DG, Gebski VJ. Methadone dose and heroin use during maintenance treatment. Addiction. 1993;88(1):119-24.

26. Rhoades HM, Creson D, Elk R, Schmitz J, Grabowski J. Retention, HIV risk, and illicit drug use during treatment: methadone dose and visit frequency. Am J Public Health. 1998:88(1):34-9.

27. Best D, Gossop M, Stewart D, Marsden J, Lehmann P, Strang J. Continued heroin use during methadone treatment: relationships between frequency of use and reasons reported for heroin use. Drug Alcohol Depend. 1999;53(3):191-5.

28. Dobler-Mikola A, Hattenschwiler J, Meili D, Beck T, Boni E, Modestin J. Patterns of heroin, cocaine, and alcohol abuse during long-term methadone maintenance treatment. J Subst Abuse Treat. 2005;29(4):259-65.

29. Roux P, Carrieri PM, Cohen J, Ravaux I, Spire B, Gossop M, et al. Non-medical use of opioids among HIV-infected opioid dependent individuals on opioid maintenance treatment: the need for a more comprehensive approach. Harm Reduct J. 2011:8:31.

30. Cao XB, Yin WY, Pang L, Zhang CB, Xu JS, Xiao YK, et al. Risk factors which were associated with heroin use during the methadone maintenance treatment among 1301 patients in 9 cities of China. Zhonghua Liu Xing Bing Xue Za Zhi. 2010;31(3):269-72.

31. Cruber VA, McCance-Katz EF. Methadone, buprenorphine, and street drug interactions with antiretroviral medications. Curr HIV/AIDS Rep. 2010;7(3):152-60.

32. Faggiano F, Vigna-Taglianti, Versino E, Lemma P. Methadone maintenance at different dosages for opioid dependence. Cochrane Database Syst Rev. 2003;3, CD002208.

33. Li L, Sangthong R, Chongsuvivatwong, McNeil E, Li J, Multiple substance use among heroin-dependent patients before and during attendance at methadone maintenance treatment program, Yunnan, China. Drug Alcohol Depend. 2011;116(1-3):246-9.

34. Raistrick D, Hay A, Wolff K. Methadone maintenance and tuberculosis treatment. BMJ. 1996;313(7062):925-6.

35. Deiss RG, Rodwell TC, Garfein RS. Tuberculosis and illicit drug use: review and update. Clin Infect Dis. 2009:48(1):72-82.

36. Wong $\mathrm{K}-\mathrm{H}$, Lee $\mathrm{S}-\mathrm{S}$, Lim W-L, Low $\mathrm{H}-\mathrm{K}$, Adherence to methadone is associated with a lower level of HIV-related risk behaviors in drug users. J Subst Abuse Treat. 2003;24(3):233-9.

\section{Submit your next manuscript to BioMed Central and take full advantage of:}

- Convenient online submission

- Thorough peer review

- No space constraints or color figure charges

- Immediate publication on acceptance

- Inclusion in PubMed, CAS, Scopus and Google Scholar

- Research which is freely available for redistribution 